\title{
RECREAR EL SELFIE
}

\section{ESTRATEGIAS EDUCATIVAS PARA LA REFLEXIÓN CREATIVA Y LA RECONSTRUCCIÓN SIMBÓLICA DE LA IDENTIDAD}

\author{
SELFIE RECREATION. EDUCATIONAL STRATEGIES \\ FOR CREATIVE REFLECTION AND THE SYMBOLIC \\ RECONSTRUCTION OF IDENTITY
}

\begin{abstract}
Sabela Eiriz
Universidad de Granada (D) https://orcid.org/0000-0002-3058-839X

\section{Resumen}

Este artículo aborda la enseñanza de la fotografía contemporánea a través de la reflexión conceptual y de la creación fotográfica en un contexto capitaneado por las redes sociales rebosantes de imágenes, en el que la intimidad y la autorepresentación tienen un papel fundamental. Se trata de una investigación educativa basada en las artes desarrollada a través de tres aciones artísticas en las que el alumnado reflexiona -con palabras y con imágenes- sobre los usos de las redes sociales y su influencia en las prácticas artísticas contemporáneas, la exhibición de la intimidad, el relato fotográfico y la proyección de la identidad a través de la fotografía.
\end{abstract}

\section{Palabras clave}

Fotografía contemporánea; narrativa fotográfica; educación artística; redes sociales; post-adolescencia.

\begin{abstract}
This article focuses on contemporary photography teaching through conceptual reflection and photographic creation. The dominant theme of this research is social media, which is filled with self-representing and intimacy lead images. This is an art education research based in the artistic actions of a group of students who - through words and images - reflect on the purposes of social media and its influence in contemporary artistic practices such as privacy exposure, photographic narration and the projection of identity through photography.
\end{abstract}

\section{Key words}

Contemporary photography; narrative photography; artistic education; social media; post-adolescence. 


\section{APROXIMARSE A LA FOTOGRAFÍA A TRAVÉS DE LA CONTEM- PORANEIDAD}

Esta investigación se desarrolló con el alumnado de Fotografía durante un mes y medio de estancia en el centro como profesora en formación dentro del prácticum del Máster de Profesorado de Artes Plásticas y Visuales. En este contexto, me encuentro con la posibilidad de escoger la materia en la que quiero desarrollar mi propuesta y opto por la asignatura de Teoría de la fotografía, cuyo contenido es fundamentalmente teórico. Mi intención es abordar las tendencias conceptuales y visuales de la fotografía contemporánea a través de una metodología indagadora que combine teoría y práctica, y que propicie en el alumnado tanto la reflexión conceptual como la creación fotográfica.

En un contexto capitaneado por las redes sociales rebosantes de imágenes, en el que la intimidad y la auto-representación tienen un papel fundamental, salen a la luz dos focos conceptuales que se abordarán mediante la investigación visual: la exhibición de la intimidad y la proyección de la identidad a través de la fotografía. Las redes sociales son uno de los principales canales de expresión y comunicación de las nuevas generaciones, y han supuesto un antes y un después en la creación de nuevos hábitos y la reconstrucción de los símbolos. Hoy en día, se observan y generan imágenes de manera continua y masiva, tanto con un fin comunicativo como de expresión individual. Por ello, se busca incentivar una actitud crítica y reflexiva en el alumnado atendiendo a las numerosas prácticas artísticas que atienden al importante papel que juegan la fotografía y las redes sociales a la hora de construir y deconstruir la identidad y configurar nuestro discurso.

Esta investigación educativa basada en la fotografía se articula a través de una metodología artográfica de indagación cualitativa en la que mi condición de artista, de docente y de investigadora se unen en un equilátero que trata de abordar todas las circunstancias que relacionan el arte con la educación y la investigación. El proceso de enseñanza-aprendizaje se desarrolla a través de la vivencia de acciones y procesos artísticos y educativos de manera interconectada entendiendo el aula como un laboratorio de experimentación (Mesías-Lema, 2017). Tomando como referencia el proceso creativo del artista, la metodología de enseñanza se transforma en experiencia y las dinámicas se corresponden y aplican en los proyectos del alumnado (Mesías-Lema, 2019, p.15). Se piensa a través de los conceptos y la teoría, pero también de la propia imagen, mediante instrumentos en los que las imágenes tienen el mismo valor de investigación que el texto (Marín Viadel y Roldán, 2014).

La investigación se desarrolla a través de tres acciones artísticas en las que el alumnado reflexiona (con palabras y con imágenes) sobre los usos de las redes sociales, su influencia en las prácticas artísticas contemporáneas, la actividad fotográfica intimista y la construcción identitaria mediante el relato fotográfico. Las dos primeras acciones, llevadas a cabo en el aula, abordan directamente la actividad fotográfica en Instagram: en la primera (Dime a quién sigues y...), reflexionaremos sobre las prácticas intimistas y extimistas ${ }^{1}$ del mundo online y, en la segunda, focalizaremos en cómo se lleva a cabo la auto-representación. En la tercera y última acción, saldremos de Instagram hacia nuestro interior para reflexionar sobre la creación personal de la identidad, poniendo en marcha las herramientas del discurso visual para construir un autorretrato. 


\section{DIME A QUIÉN SIGUES Y... INTERVENCIÓN CON EL ALUMNADO EN EL RELATO VISUAL SOCIAL DIGITAL}

Desde la democratización de la fotografía, hemos aprovechado la capacidad de esta técnica parar capturar los elementos que delimitan nuestro contexto y que configuran nuestra identidad, para construir una crónica visual de nuestra vida que funcione como testimonio observable (Sontag, 2009). En los últimos años, esta práctica se ha visto fomentada por la expansión de las redes sociales y la implementación de los smartphones, convirtiendo en algo habitual el registro fotográfico de eventos, viajes o encuentros sociales, y su consiguiente difusión en una red de usuarios, más o menos amplia y conocida. El gesto fotográfico se convierte en un acto de relación, de comunicación interpersonal que «más que reflejar el acontecimiento, lo que desea es manifestar nuestra presencia en ese acontecimiento" (Fontcuberta en Alonso, 2013). En este contexto virtual, los límites de la intimidad y de la privacidad pueden verse comprometidos: si bien las plataformas sociales ofrecen ciertas herramientas para restringir la difusión del contenido, ni todos somos conocedores de ellas ni todo aquello que compartimos queda bajo nuestro control único. En ese sentido, la privacidad tiene tanto que ver con lo que decidimos mostrar, como con el control que tenemos al hacerlo. La problemática reside cuando la búsqueda de autoafirmación se convierte en una rutina en la realidad virtual, una obsesión por certificar la existencia, por burlar el tiempo y la desaparición (Aguilar-Nuevo y Lara-Barranco, 2011, p. 532), imponiendo el pensamiento de que es necesario ser en lo virtual para ser en lo real. Todo ello, en un entorno en el que predomina el 'yo' frente al colectivo y la presión social a formar parte de las tendencias y de los fenómenos más actuales (Saavedra Vásquez, 2017, p. 201). No sólo vivimos rodeados de imágenes, también vivimos a través de ellas. Generamos vivencias visuales para construir nuestra vida y compartirla, material e inmaterialmente.

A la hora de abordar con el alumnado las tendencias de la fotografía contemporánea, me detengo ante las propuestas intimistas y autobiográficas de artistas como Félix González-Torres, cuyas intervenciones artísticas parten de sus experiencias personales, y en las exposiciones mosaico de Rinko Kawauchi y el fotolibro everything will be ok de Alberto Lizaralde, quienes capturan fragmentos de su día a día para construir un diario conceptual y visual. Observamos conjuntamente cómo la fotografía no es sólo un medio para capturar nuestra cotidianeidad, sino que este mismo lenguaje puede traspasar los límites de lo privado y participar en el ámbito artístico. A raíz de estas prácticas, nos adentramos en el relato meta-fotográfico de artistas como Laia Abril, Amalia Ulman o Eva \& Franco Mates, donde esa exposición intimista está atravesada por las prácticas actuales en las redes sociales, en las cuales exhibimos nuestra autobiografía con un mayor o menor grado de ficción y de control sobre las imágenes. Una vez más, los límites entre lo privado y lo público se difuminan y dependen de un discurso conceptual y artístico.

A partir de esta confluencia entre las prácticas artísticas y la actividad fotográfica predominante en el mundo virtual, invito al alumnado a investigar y reflexionar sobre las fotografías que se comparten en una red social eminentemente fotográfica: Instagram. Intentando huir de los prejuicios, atendemos grupal e individualmente a los patrones más habituales a la hora de compartir nuestra autobiografía visual y las formas de uso y consumo de esta red social. La propuesta que traslado al alumnado consiste en desarrollar esta reflexión con el propio lenguaje fotográfico, apropiándose de imágenes que encuentren en Instagram e interviniéndolas mediante la inserción de texto.
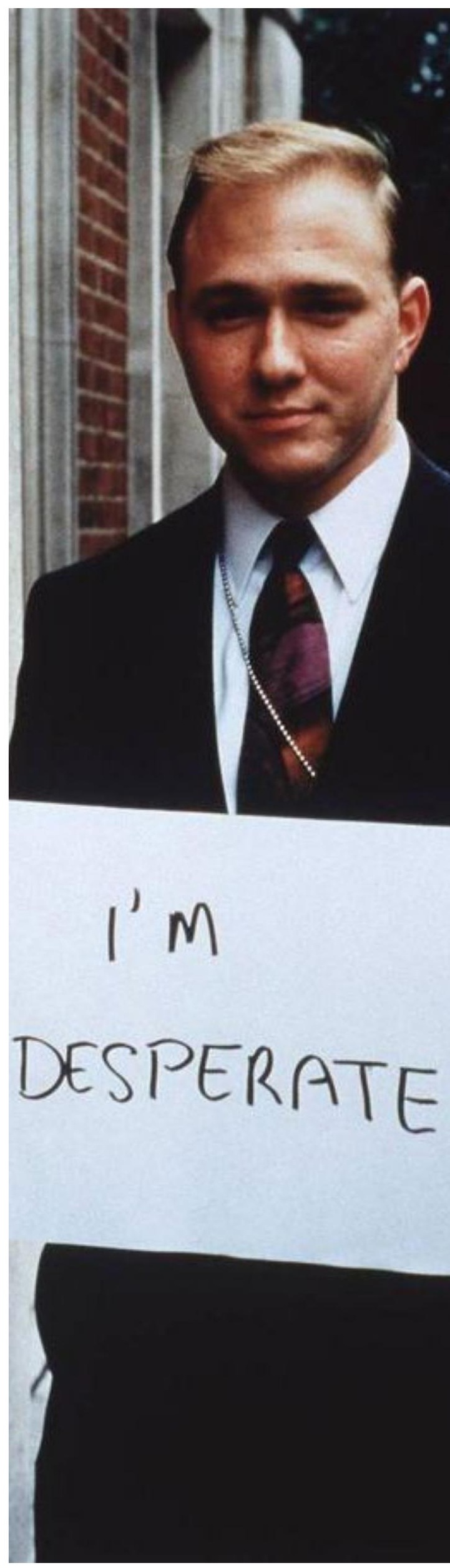

Imagen 2. Gillian Wearin, 1992-1993. 
A modo de referentes artísticos, comparto dos proyectos en los que se intercala fotografía y texto y se enriquece el valor simbólico de ambos lenguajes. Por un lado, Signs that say what you want them to say and not Signs that say what someone else wants you to say de Gillian Wearin (imagen 2), con el que la artista revela la conexión entre el interior y el exterior de la vida personal, y entre el individuo y la sociedad, fotografiando a personas desconocidas sujetando un letrero en el que han escrito previamente sus pensamientos $\mathrm{u}$ opiniones, respuestas honestas que rompen estereotipos y redireccionan la mirada sobre ellas. Por otro lado, les muestro también la obra de Kenneth Lum, en la que cada pieza fotográfica está acompañada de un texto repetitivo que redefine y reconstruye lo que ocurre en la imagen, generando nuevos significados.

El desarrollo de la acción se lleva a cabo en pequeños grupos que, durante unos minutos, rastrean sus cuentas de Instagram para localizar imágenes que intervenir. Durante ese tiempo, me aproximo a cada uno de ellos para detectar posibles dudas o bloqueos y ser de ayuda en su desarrollo creativo. La mayor parte del alumnado tiene dos cuentas de Instagram, una para compartir contenido personal y otra dedicada a su actividad profesional y les animo a realizar la búsqueda en la primera. Pasado el tiempo de trabajo, vemos todas las imágenes en el aula. Cada grupo presenta sus ideas y comentamos las impresiones que se desprenden, analizando el mensaje que se quiere transmitir y el funcionamiento del texto, de las imágenes y de ambos en conjunto.

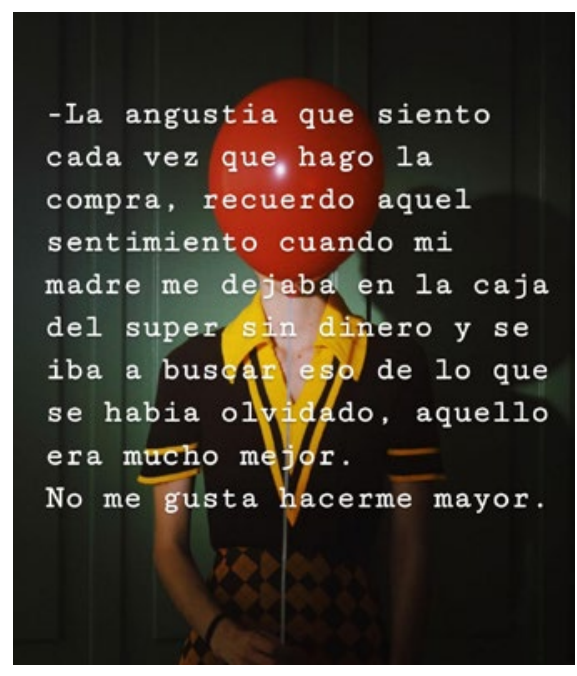

Imagen 3. Antía Durán y Miriam Díaz, 2020.

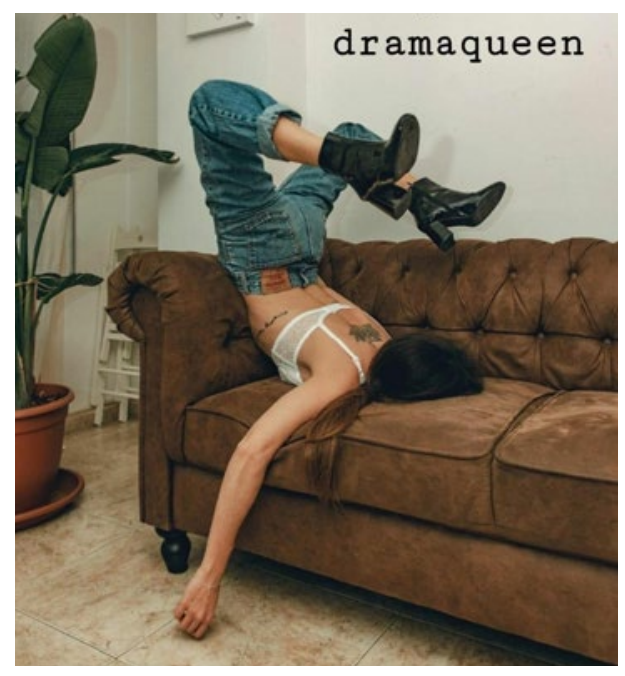

Imagen 4. Sergio Quintáns y Sara Costas, 2020.

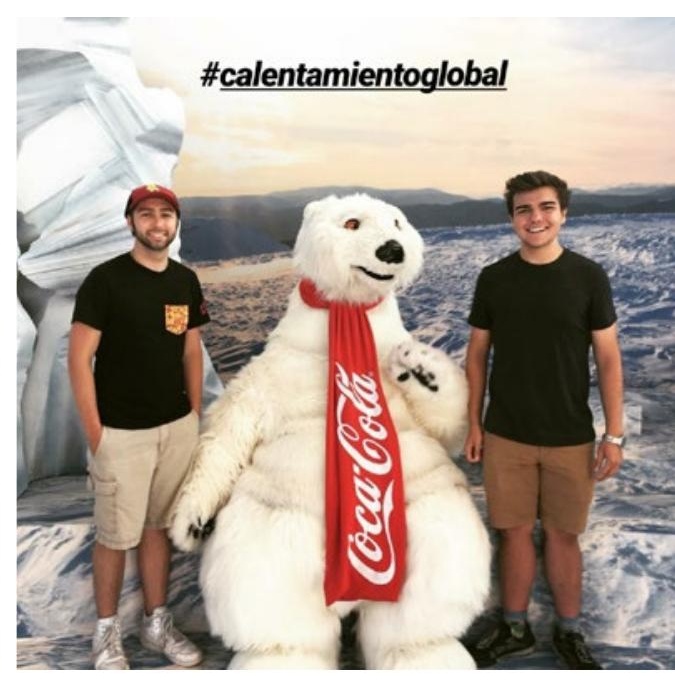

Imagen 5. Antía Durán y Miriam Díaz, 2020.

A pesar de mi recomendación, una parte de los trabajos seleccionó imágenes del mundo de la publicidad, de la moda o incluso del arte (imagen 3), y la reflexión sobre los comportamientos y las dinámicas habituales de las redes queda oculta. Aprovecho para recalcar la relevancia que tiene, en este tipo de procesos creativos, la selección de imágenes, y cómo puede determinar los resultados de nuestro proyecto. Sin intención de tachar su criterio, trato de que comprendan la idoneidad y las posibilidades narrativas de cada imagen. Igualmente resulta interesante observar cómo, aunque no hablen de las dinámicas en la red, sí desvelan la propia identidad y los intereses de este alumnado, usuario habitual de Instagram. Me sorprendo al encontrar un discurso joven, en una marcada adolescencia tardía, que se siente en el tiempo de descuento de esta etapa vital. También observamos cómo, a través de la integración de texto, la imagen se convierte en otra cosa, más o menos cercana a la original, abriendo nuevas interpretaciones.

Las propuestas del alumnado hacen referencia a las tendencias más habituales en las fotografías de Instagram, poniendo en duda su forma y sus estrategias visuales (imagen 4). Recurren a la sátira y a la denuncia a través de un mensaje más o menos ácido que atrapa la mirada, viajando del texto a la imagen y de la imagen al texto (imagen 5). En esta misma línea, otras intervenciones que inciden directamente en la actividad intimis- 
ta-exhibicionista de la red (imagen 6) son combinadas con textos provenientes del propio Instagram. De esta forma, cuestionan, a través de su propio lenguaje, las dinámicas que se dan en esta aplicación y el control que pueden ejercer sus usuarios.

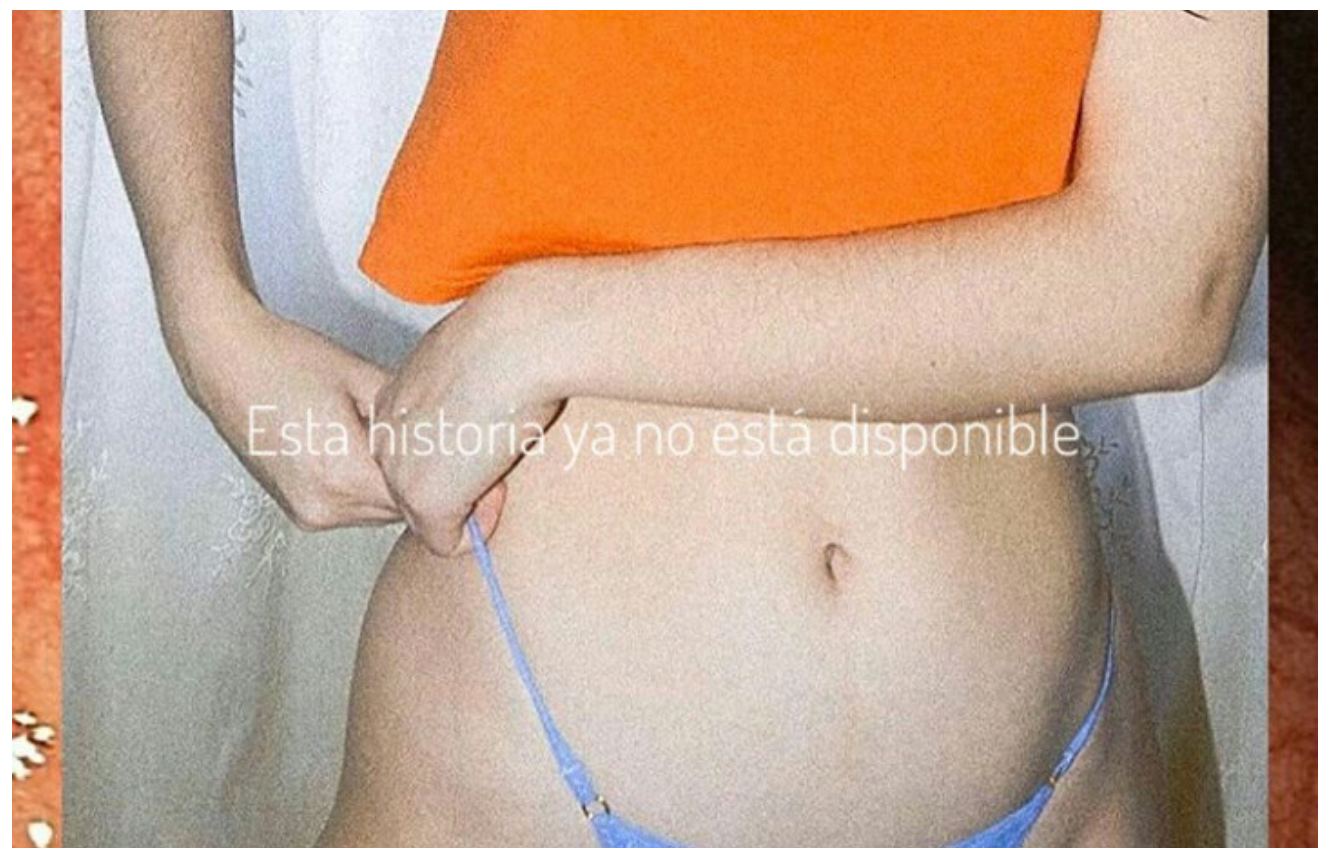

Imagen 6. Alba Pérez, Sara Muíños y Natalia Pérez, 2020.

Esta primera acción con el alumnado supone el primer acercamiento con un grupo complejo y silencioso que me observa y escucha por primera vez. Sus respuestas y propuestas suponen el punto de partida para observar, pensar y hablar sobre la fotografía contemporánea y su entorno más directo y familiar como es Instagram.

\section{HAPPYGRAM. HABLAR DE LA IMAGEN CON LA IMAGEN}

Internet es el espacio propicio para la exhibición de la intimidad ante un público que lo observa a través de su pantalla y en el que el 'yo' asume el papel de autor, narrador y personaje. El material biográfico compartido en la happygram responde a menudo a tendencias caracterizadas por la felicidad, el bienestar y la perfección. Dentro de toda esta actividad fotográfica, nos encontramos con una imagen estrella: el selfie, el autorretrato mediatizado más famoso de esta era. El selfie no es sólo una tipología del autorretrato, sino un subgénero de las imágenes que se comparten en las redes sociales y cuyas características van más allá del mero deseo de autorrepresentación (Ayerbe y Cuenca, 2019, pp. 3-4). Los prejuicios que a menudo recaen sobre internet dificultan visualizar la red como un entorno de dinámicas sociales posibles más allá del ego, de la misma forma que las opiniones negativas que tachan al selfie de acto egocentrista no siempre permiten abordar su también carácter empoderador de definición e intervención en el entorno inmaterial de la red mediante la imagen de nuestro rostro y nuestro cuerpo.

A través de una mirada abierta y crítica, me acerco con el alumnado al fenómeno ambivalente del selfie y su gran presencia en la red. Exponer la intimidad es una forma de constatar la existencia y de definir lo que somos, de certificar el aquí y el ahora ante un público que nos observa a través de la pantalla, pero también de construir una narración que trascienda la realidad. Entre los discursos íntimos compartidos en Internet, podemos distinguir dos tendencias principales: la autoficción (cuyo contenido tiene un marcado carácter comercial) y la vulnerable (con un discurso íntimo). Ambas comparten las paradojas contradictorias del lenguaje virtual y las características resbaladizas de este tipo de comunicación, y ambas comienzan como ejercicios individuales que se desarrollan a nivel colectivo, creando una nueva modalidad de relación grupal (Canga Sosa, 2015, p. 401). Tomando como precedente las prácticas fotográficas contemporáneas que cues- 
tionan la veracidad de la imagen, nos preguntamos: ¿funcionan estas fotografías como extracto vívido de nuestro día a día y representación fidedigna de nuestra identidad?

En esta segunda acción con el alumnado, les propongo cuestionar aquellas dinámicas que se ponen en marcha a la hora de mostrar y percibir la identidad en Instagram, apropiándose de imágenes y reinterpretándolas (interviniéndolas con collage o edición digital, o a través del remake), para promover el desarrollo de la reflexión a través de la construcción de la imagen. A la hora de proporcionar referentes artísticos y fotográficos, les expongo el trabajo de Joan Fontcuberta $A$ través del mirall (en el que el artista y teórico trabaja con imágenes tomadas de redes sociales), la provocadora exposición de Richard Prince New Portraits (para la cual se apropió de imágenes de Instagram sin solicitar permiso a sus autores) y los collages de Intimidad Romero expuestos online y que consisten en fotografías intervenidas con píxeles, creando una realidad inquietante que destruye las formas de representación. Tres trabajos en los que sus creadores cuestionan de formas muy diferentes el control y el interés en mostrar la intimidad online.

Por otro lado, les acerco también el trabajo fotográfico de Celeste Barber (imagen 7), el cual cuestiona las imposiciones al cuerpo en la sociedad y reflexiona sobre las prácticas en redes sociales a través de la reconstrucción de fotografías 'imposibles' de personas famosas con posturas difíciles y cuerpos perfectos, mostrando una versión cotidiana de las mismas. Además, considero interesante tener en cuenta la actividad que la artista Cindy Sherman lleva a cabo actualmente en su cuenta de Instagram, plagada de selfies distorsionados a través de filtros y retoques digitales, reinterpretando su propio trabajo artístico con las herramientas que ofrece esta aplicación.

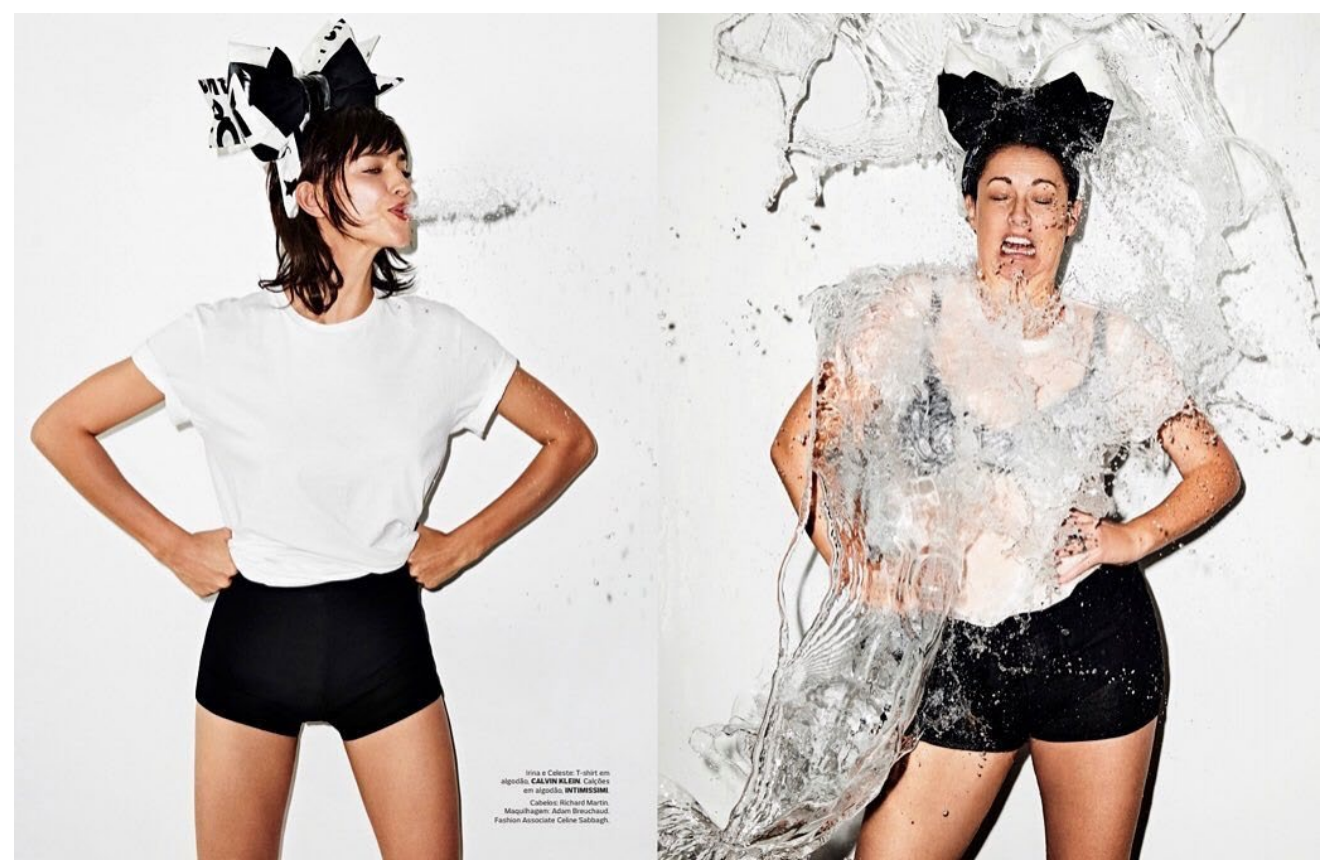

Imagen 7. Celeste Barber, 2019.

Organizo de nuevo la clase en pequeños grupos para que hagan un recorrido por Instagram y seleccionen imágenes con las que desarrollar la acción. Mientras, yo les observo de cerca, acercándome a cada grupo para conocer sus ideas y detectar, una vez más, posibles dudas o bloqueos. Cuando terminan, visionamos las propuestas, cada grupo explica brevemente el contexto y la dirección de su imagen, y comentamos su eficacia.

Todas las propuestas tienen un tinte cómico que alude a las posturas y a los gestos que encuentran en Instagram. La interpretación de estas imágenes se lleva a cabo a través de la comparación y el paralelismo con otras fotografías sacadas de Internet. A la hora de colocarlas una al lado de la otra, las fotografías dialogan entre sí y reconstruyen su discurso. De esta forma, los autorretratos hieráticos se convierten en imágenes de una 
ficha policial (imagen 9) y las posturas imposibles utilizadas en la fotografía de moda ven alterado su significado en términos de parodia (imagen 10). Con estos pequeños gestos, el alumnado detecta algo sobre lo que le interesa hablar y genera un discurso sencillo pero efectivo a través de la disposición y la combinatoria de imágenes fotográficas.

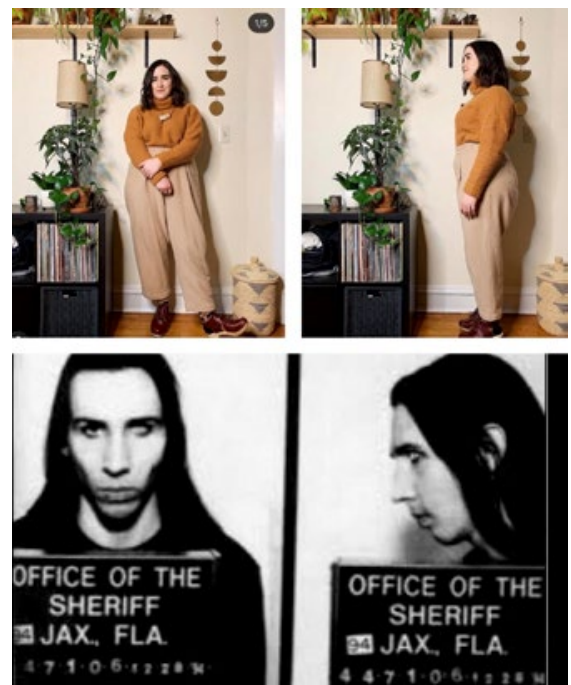

Imagen 9. Sara Costas y Malena Montejo, 2020.

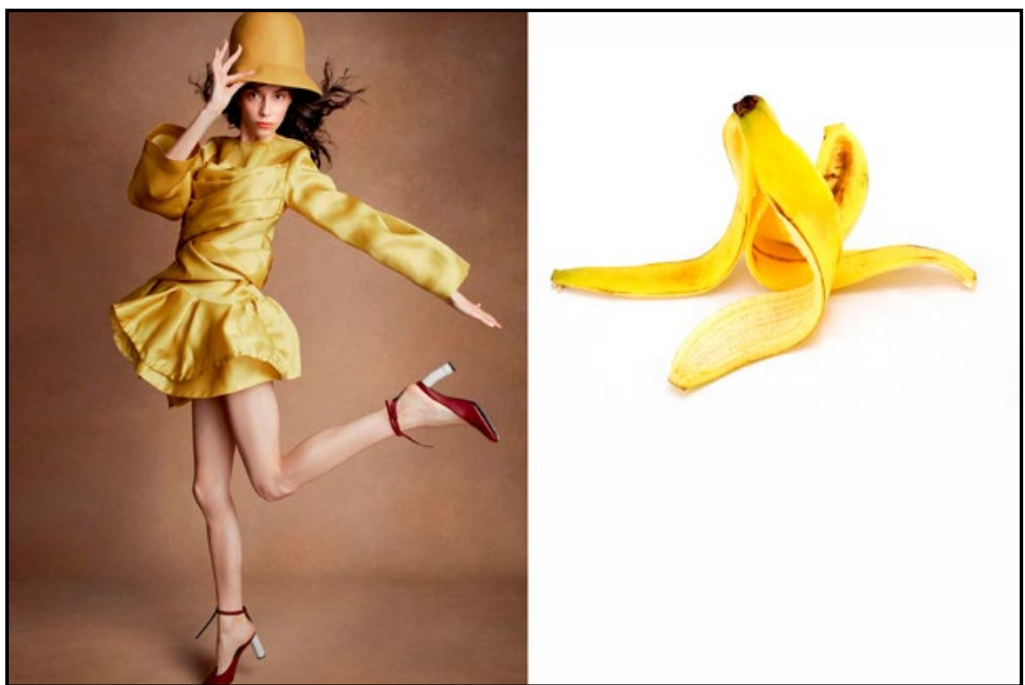

Imagen 10. Sara Costas y Malena Montejo, 2020

Abordan también la compulsión del acto del selfie que podemos observar en cuentas de Instagram repletas de imágenes prácticamente idénticas debido a que el usuario se fotografía una y otra vez con la misma expresión. Las alumnas fotografían una estatua aplicando sobre ella diferentes filtros que Instagram ofrece para la distorsión del rostro, generando nuevas expresiones para unos rasgos que son absolutamente inmutables. La composición resultante presenta la referencia de Instagram en paralelo a las fotografías tomadas, construyendo su discurso visual y conceptual de manera precisa e irónica.

\section{ALTER-SELFIE. CREACIÓN ARTÍSTICA Y FOTOGRÁFICA CON EL ALUMNADO}

Después de haber abordado el contexto y las prácticas de la fotografía contemporánea, de ponerlas en relación con el entorno mediático de Instagram y de trazar los caminos en los que delimitamos y percibimos nuestra identidad, planteo al alumnado una última acción: construir un discurso fotográfico a través del autorretrato. Lo presento como un ejercicio personal, invitando a la reflexión y al desarrollo conceptual sobre la identidad propia mediante la producción fotográfica. Es por ello que en esta ocasión el trabajo se hará fuera del aula y con varios días para su ejecución. El único requisito que les pongo a la hora de conceptualizar y realizar el autorretrato es partir de un objeto. De esta forma, promuevo un punto de partida común para trazar la idea y la narración visual de la imagen, asegurando así una trayectoria discursiva. Se trata de un pretexto que pueda iniciar o guiar un proceso tan abierto como es autorretratarse. Por otro lado, les pido que cada fotografía vaya acompañada de un texto en el que expliquen su proceso creativo, el concepto que quieren expresar y de qué forma deciden plasmarlo para conocer y valorar la efectividad de la imagen y de su discurso.

Dentro de la gran variedad de propuestas en sus trabajos, observo un despliegue emocional e íntimo muy profundo que les agradezco personalmente. Al fin y al cabo, se trata de un alumnado que apenas me conoce -ni yo a él-, y, sin embargo, una parte de ellas y ellos se vuelve transparente en tanto que han decidido confiar en esta acción creativa para mostrar sus ideas y sus conflictos mediante el lenguaje fotográfico. Me encuentro con personas que tienen ganas de hablar, con preocupaciones individuales y comunes más o menos acorazadas o vulnerables. En todos los aspectos, se trata de material sensible que ha desplegado sus pensamientos, sus intereses y sus preocupaciones en 
primera persona, despertando vínculos entre sí, identificándose de manera individual pero también común. Por ello, es un autoconocimiento personal, pero también grupal.

La mayor parte de los proyectos tratan temáticas relacionadas con el aspecto. Aparecen repetidamente elementos como el maquillaje, los espejos y otros objetos y símbolos que aluden o afectan al físico. Los espejos revelan una búsqueda, un encuentro y, en ocasiones también, un enfrentamiento. Suponen una manera de exploración propia, de «adentrarse en uno mismo, perderse en los pensamientos (...) buscando la calma interior» (Malena Montejo, imagen 11).

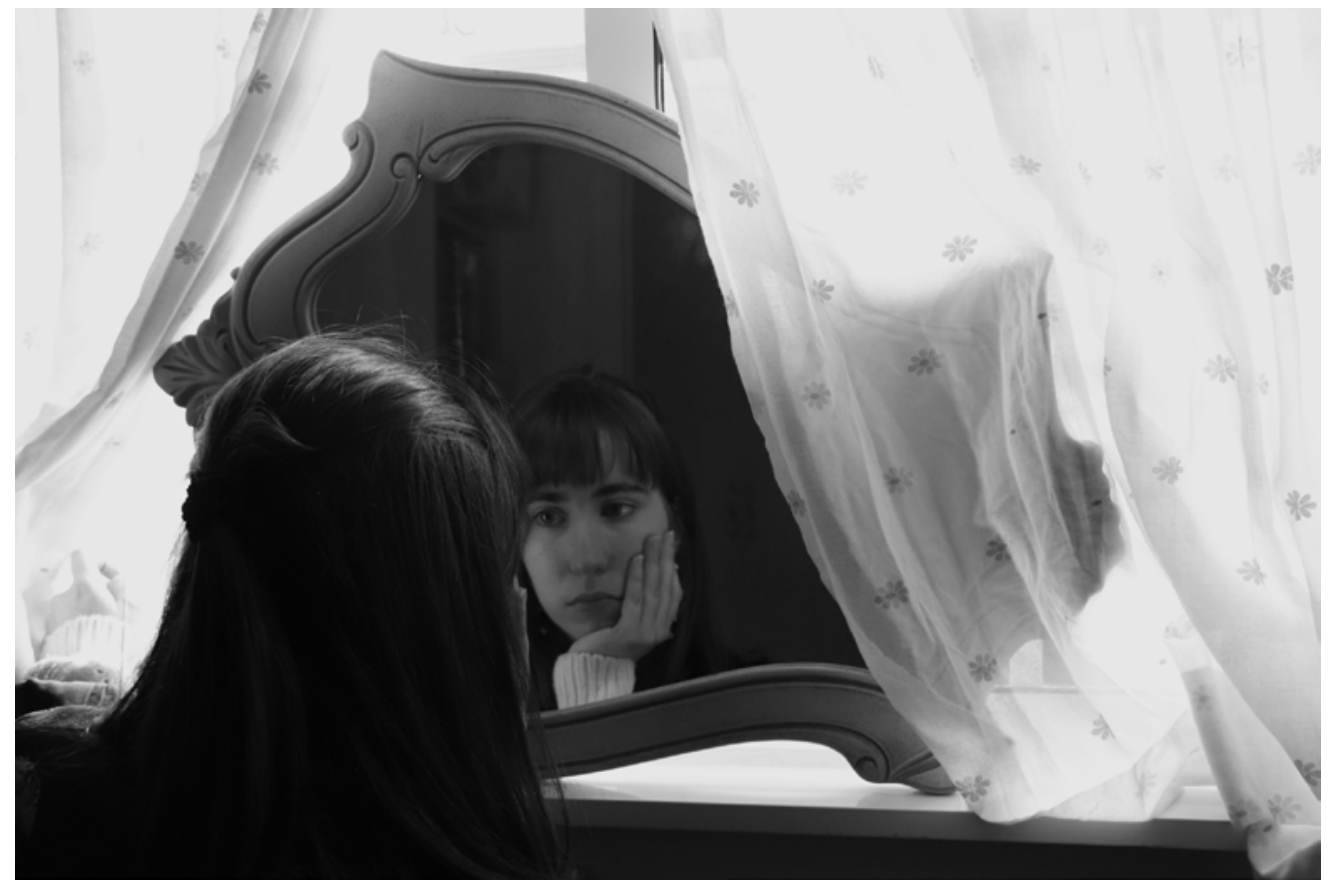

Imagen 11. Malena Montejo, 2020.

Ese reflejo está presente también en la pantalla del teléfono, que nos devuelve una imagen a tiempo real como una busca y captura continua de lo real. Otorgan al reflejo y a la imagen su estatus de realidad, su entidad como representación, abordando «dos realidades: una analógica, real, de contacto humano (...) y otra completamente digital, la de las redes sociales (...). Hoy en día somos una parte real con interacción real con gente real, pero por otra parte somos digitales con relaciones sociales exclusivas dentro del ámbito digital» (Daniel Muñiz Torres, imagen 12).

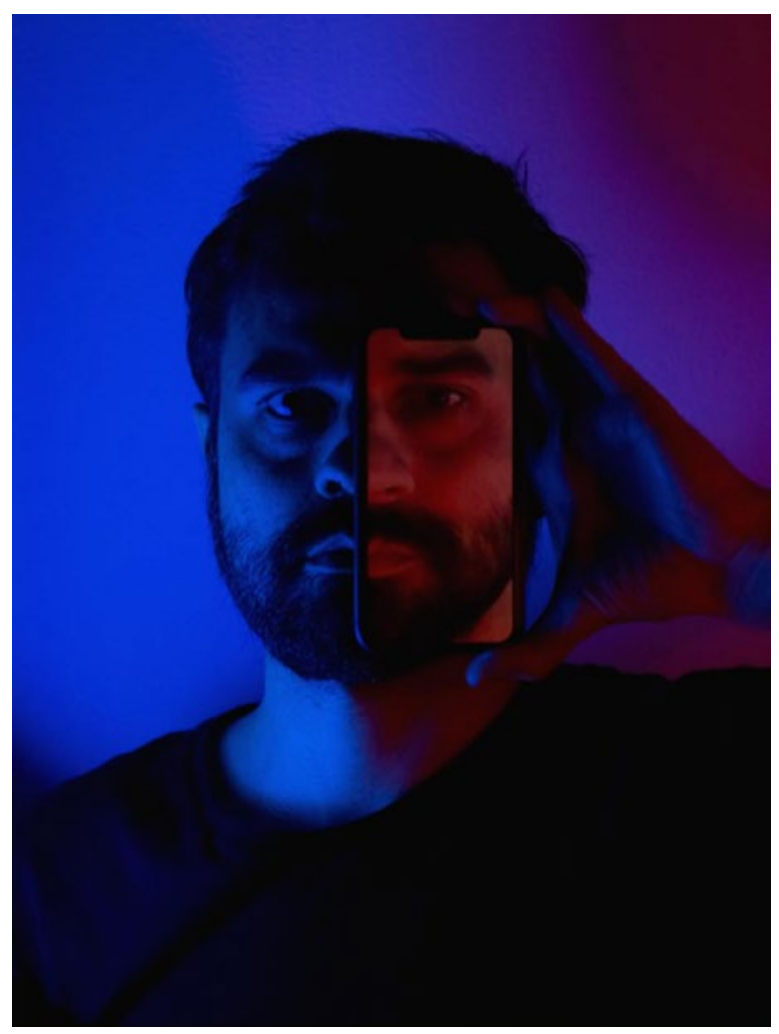

Imagen 12. Daniel Muñiz Torres, 2020. 
En esa performance de la identidad, intervienen ornamentos que a menudo complementan nuestro rostro o nuestro físico. Encontramos dos posiciones que se enfrentan a estereotipos y convenciones sociales: por un lado, entender el maquillaje como decisión propia y complemento, que no tapa sino que significa (imagen 13); por el otro, combatir la necesidad de corregir y ocultar, desvelando «la lucha interior de una persona consigo misma. El intentar verse bien físicamente y no conseguirlo» (Natalia Pérez, imagen 14). Estas imágenes no tratan tanto de mostrar la intimidad, sino de compartirla, poniendo un poco de luz en aquello que tratamos de mantener a oscuras.

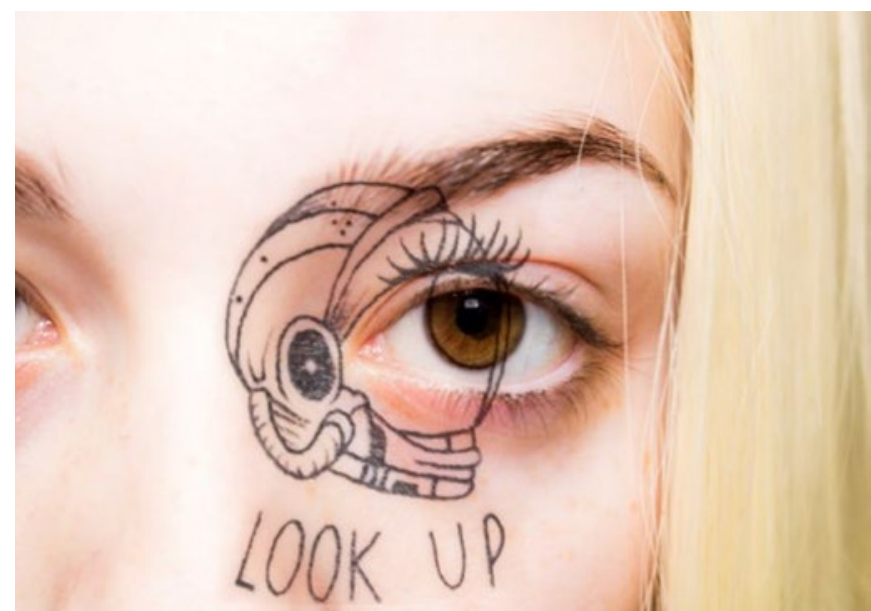

Imagen 13. Iria Rosende, 2020.

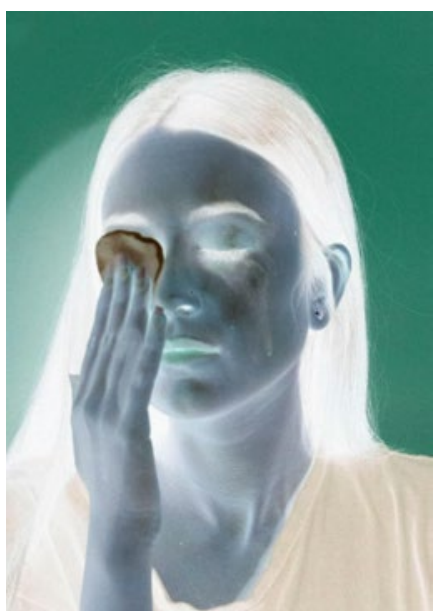

Imagen 14. Natalia Pérez Martínez, 2020.

Aparecen también fotografías con mayor performatividad y cuya narración se aleja del relato personal, construyendo una imagen cotidiana e íntima que se transforma en una ficción agresiva pero que, a pesar de todo, sigue hablando de la propia autorretratista (imagen 15). Su interés no es sólo lo que se busca decir y transmitir, sino también en lo que podemos intuir del inconsciente, lo que revela sobre su autoría.

Son recurrentes también las fotografías que intervienen sobre el cuerpo con elementos que remiten a una imposición social externa. El autorretrato nos lleva a una implicación social, a una preocupación por problemáticas más allá del relato autobiográfico. Las marcas que intervienen en el rostro, tapándolo (imágenes 16 y 17) responden a referencias conocidas en nuestro imaginario: el parche, la opresión, el abuso sobre el cuerpo.

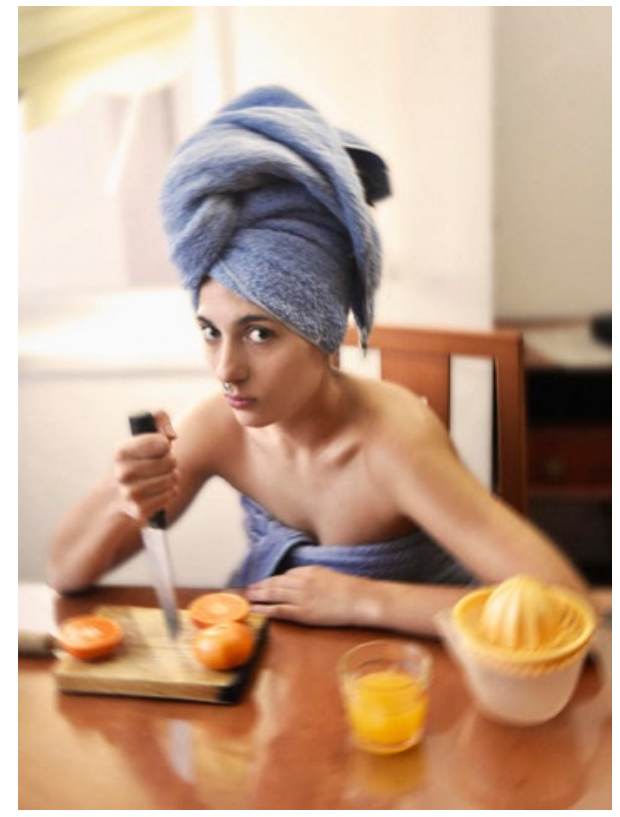

Imagen 15. Sara Costas, 2020.

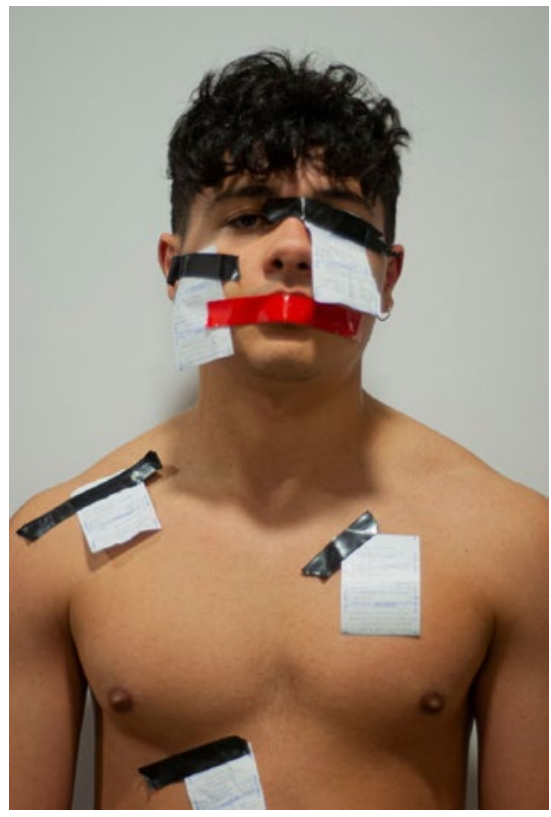

Imagen 16. Miguel Rodríguez, 2020.

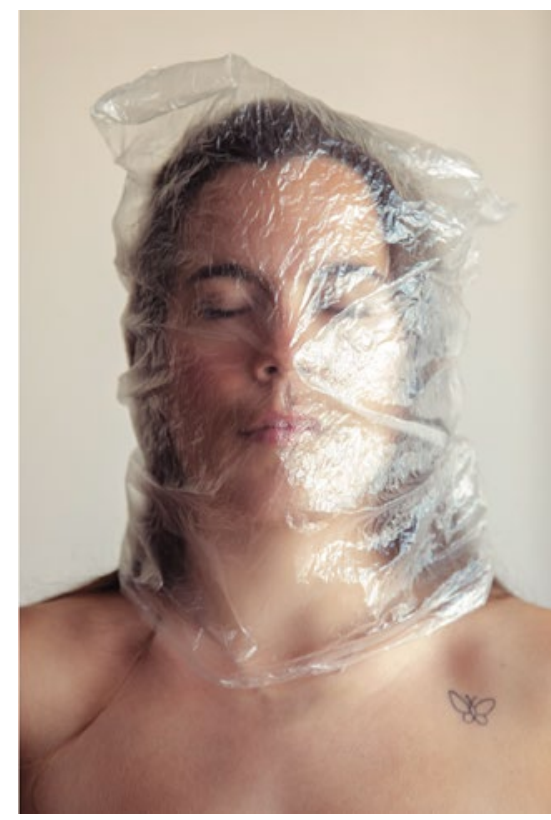

Imagen 17. Alba Pérez, 2020. 
Esta opresión toma forma en otro tipo de materiales, como el plástico en el cuerpo que remite directamente a la ansiedad. «Recuerdo que cuando era pequeña mi madre tenía pánico de que me pusiera una bolsa de plástico en la cabeza y me ahogara. Quizá fuera porque tenía la mala costumbre de hacerlo. Siempre me ha gustado aislarme del mundo» (Alba Pérez, imagen 17). Una vez superada la primera impresión sobre la bolsa, más evidente, podemos fijarnos en los elementos que significan en la imagen, y en cómo ese plástico que limita el aire se contradice con un rostro sereno, oculto bajo una superficie transparente que lo distorsiona pero que nos deja ver su cara.

De entre todos los autorretratos, uno de ellos escenifica en el objeto toda la puesta en escena. No hay cuerpo, y sin embargo sigue siendo un relato propio, una representación de la fotógrafa que se presenta a través de esta imagen. Su propuesta recurre a la poética de los objetos, identificándose con la acción que ocurre: la contradicción entre fuego y agua, el placer y la destrucción, la coexistencia de elementos incompatibles.

Otras imágenes, más intimistas y personales, se centran en narrativas propias y la intimidad es la protagonista. Un bodegón en el que interviene el cuerpo, como un elemento más de la cotidianeidad de la persona. Se trata de una imagen de la intimidad con un gesto fuera de lo cotidiano, haciendo evidente la puesta en escena y la intención fotográfica pero, a pesar de la performatividad, no deja de haber cierta sensación voyeur en el espectador. La mirada se convierte en un canal para la honestidad, traspasando la imagen, buscando un reflejo en el otro, un punto de apoyo en la cámara/espectador. En otro caso, la performatividad toma lugar para construir el relato propio (imagen 18). Narratividad e intimidad se unen y el escenario, preparado y atrezado, otorga atributos a un 'yo' para convertirlo en otra persona, disfrazándose para representarse. La persona es ella y es otra: «Esta no soy yo, esta soy la yo que no quiero ser, en la que no me quiero convertir» (Sara Muíños).

El autorretrato se consolida entonces como reflejo y su autoría queda definida por todas las decisiones tomadas antes, durante y después de la captura fotográfica, y construyéndose a través de su desarrollo tanto conceptual como visual.

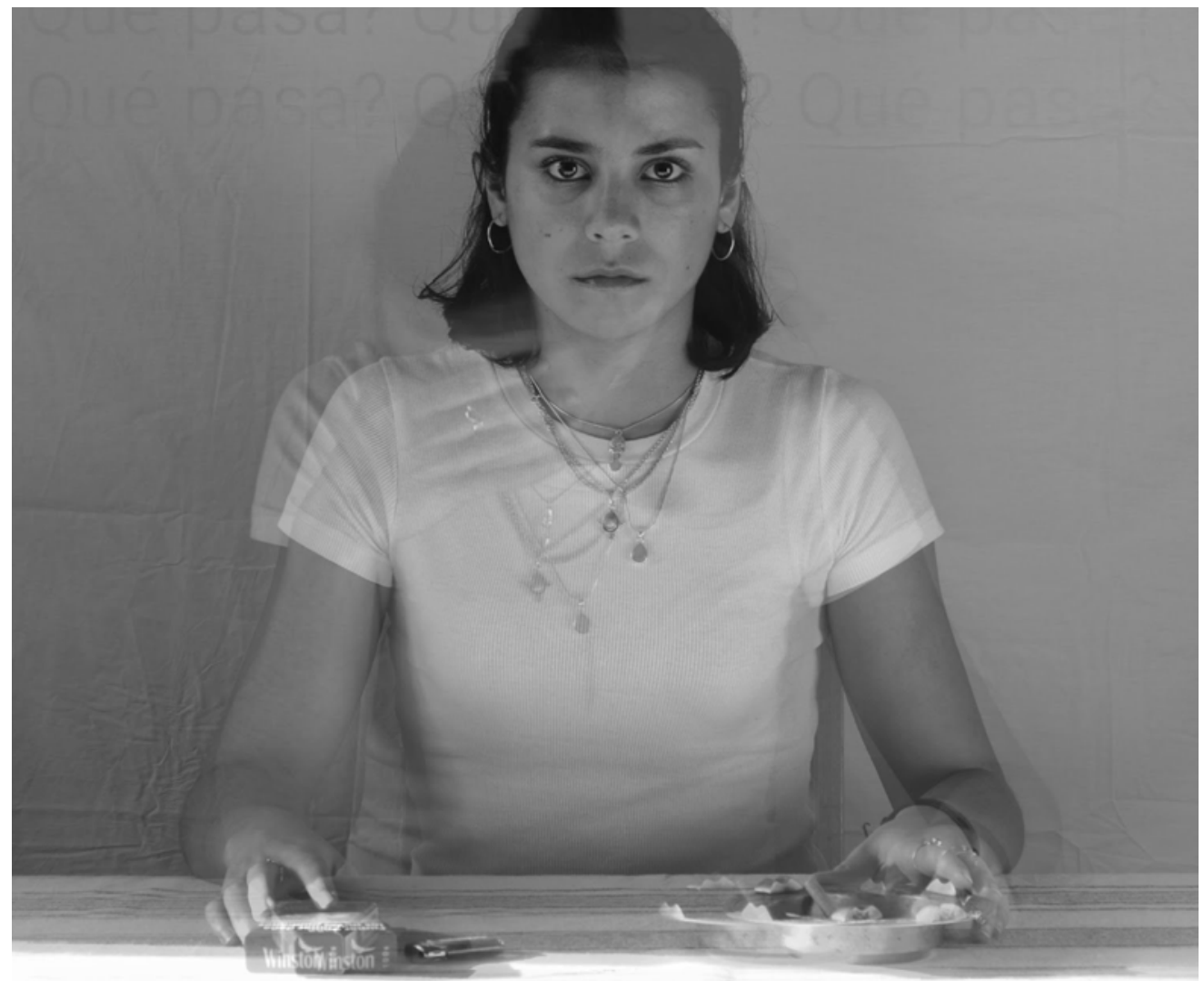




\section{EPÍLOGO}

Esta propuesta ha buscado la implicación del alumnado para abordar la realidad y las tendencias de la fotografía contemporánea desde la reflexión crítica y creativa. Gracias a esta aproximación (tanto visual como conceptual) al contexto mediático más cercano a la imagen contemporánea -y que es, al mismo tiempo, un entorno habitual y cotidiano para el propio alumnado-, se ha ahondado en nuestros hábitos de vida y uso de las redes desde diferentes lenguajes y medios artísticos, un campo temático imperante en las producciones artísticas actuales (Martín Prada, 2015, pp. 24-29). Es, por tanto, una propuesta metafotográfica, donde el mismo lenguaje que se estudia se aplica para pensar sobre sí misma, un método de trabajo habitual en las prácticas artísticas contemporáneas. Este tipo de aproximaciones permiten reflexionar sobre el trabajo propio o ajeno, comprender los límites y las relaciones entre las imágenes y/o sus referentes, o vincularlas con el contexto cultural. La propuesta de aprendizaje con el alumnado se vincula a una investigación basada en la fotografía y construida a través de texto e imagen, en tanto que el medio visual resulta fundamental a la hora de estudiar y poder comprender el mundo posmoderno (Abaker Baptista, 2014, pp. 116-117).

En cuanto a los proyectos del alumnado, cabe destacar que lo interesante de la imagen no es sólo su entidad icónica, sino lo que podemos conocer y ver a través de ella (Broullón-Lozano, 2015, pp. 223-224). Algunos de los trabajos presentados se escapan a la propuesta inicial y, sin embargo, permitieron un conocimiento más profundo del alumnado creador. Por otro lado, también se recalca cómo el selfie no tiene por qué restringirse a ser un mero escaparate, sino que todas las decisiones (más o menos conscientes) que se toman a la hora de capturar nuestra imagen y que delimitan cómo queremos ser percibidos, son también discurso. La imagen fotográfica adquiere carácter narrativo. Configurar las acciones a través del discurso visual promueve un pensamiento más allá de la palabra para contribuir a la formación fotográfica de este alumnado.

Por último, cabe destacar también cómo otros elementos han resultado claves a la hora de trabajar con un grupo especialmente hermético y poco participativo. La escucha activa, la observación y el seguimiento cercanos, las preguntas abiertas que promuevan su pensamiento y animen a la creatividad, así como construir un entorno de confianza que permita trabajar desde la emoción y la vulnerabilidad, han ayudado a que los resultados nos permitan acercarnos con honestidad y compromiso a la creación.

\section{REFERENCIAS BIBLIOGRÁFICAS}

Abaker Baptista, M. B. (2014). Fotografiar para contar otra historia: Una experiencia de formarse en grupo mediante procesos de indagación. En Marín Viadel, R., Roldán, J. y Mena de Torres, J. (eds.). (Re)Presentaciones, miradas y reflejos en Investigación basada en Artes e Investigación Artística [(Re)Presentations, glances and reflections in Arts based Research and Artistic Research] (pp. 113-125). Granada: Universidad de Granada.

Aguilar-Nuevo, R. y Lara-Barranco, P. (2011). Simulación en arte contemporáneo: creando identidades en la era de las pantallas. Laboratorio de arte 23, 523-536.

Alonso, J. (13 de junio de 2013). Joan Fontcuberta. La Postfotografía. Creadores. RTVE. Recuperado de http://www.rtve.es/alacarta/videos/creadores/aventura-del-saber-joan-fontcuberta-postfotografia/1870690/

Ayerbe, N. y Cuenca, J. (2019). El selfie como performance de la identidad. Explorando la performatividad de la auto-imagen desde el arte de acción. Papeles del CEIC, 213(2019/2), 1-16.

Baigorri-Ballarín, L. (2019). Identidades robadas. Arte, apropiación y extimidad en la vida online. Arte, Individuo y Sociedad 31(3), 605-624. 
Broullón-Lozano, M. (2015). Por una semiótica del selfie en la cultura visual digital. Fotocinema. Revista científica de Cine y fotografía, 11, 215-234.

Canga Sosa, M. (2015). Introducción al fenómeno del selfie: valoración y perspectivas de análisis. Fotocinema. Revista científica de Cine y fotografía, 10, 383-405.

Marín Viadel, R. y Roldán, J. (2014). 4 Instrumentos cuantitativos y 3 instrumentos cualitativos en Investigación Educativa basada en las Artes visuales. En Marín Viadel, R., Roldán, J. y Pérez Martín, F. (eds.). Estrategias, técnicas e instrumentos en Investigación basada en Artes e Investigación Artística [Strategies, techniques and instruments in Arts based Research and Artistic Research] (pp. 71-114). Granada: Universidad de Granada.

Martín Prada, J. (2015). Prácticas artísticas e Internet en la época de las redes sociales. Madrid: Akal.

Mesías Lema, J. M. (2019) Educación Artística Sensible. Cartografía contemporánea para arteeducadores. Barcelona: Graó.

- _ - (2017). Art Teacher Training: a photo essay. International Journal of Education through Art, 13(3): 1, pp. 395-304. https://doi.org/10.1386/eta.13.3.395 1

Saavedra Vásquez, V. (2017). Selfie como medio de comunicación del siglo XXI. Letras 88(127), 197-206.

Sontag, S. (2009). Sobre la fotografía. Barcelona: DeBolsillo. 
Sabela Eiriz es artista visual, fotógrafa y realizadora audiovisual, docente e investigadora del grupo Arte-Facto. Graduada en Comunicación Audiovisual (USC) y en los másters de Fotografía y Diseño (ELISAVA), de Estudios Comparados de Literatura, Arte y Pensamiento (UPF) y de Profesorado de ESO, Bachillerato y FP en la especialidad de Artes Plásticas y Visuales (UDC), actualmente desarrolla su doctorado en Artes y Educación por la Universidad de Granada. Paralelamente, trabaja como autónoma en los ámbitos de la fotografía, el vídeo y las artes visuales.

sabela.m.eiriz@gmail.com 